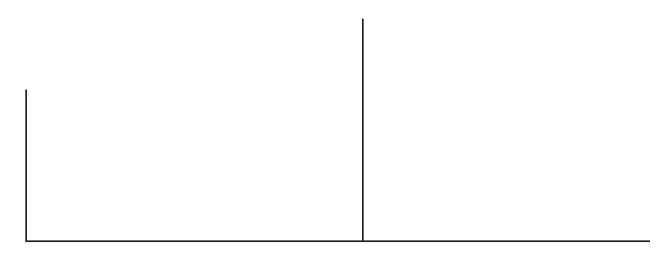

Rev. Latinoam. Psicopat. Fund., II, 2, 144-151

\title{
Los fondamentos y la persona
}

Jorge J. Saurí

La "locura", cualquiera sea su versión modal, es una eventualidad de proceso de personalización, no un acaso gratuito o azaroso, ni el obligado efecto de una causa. Conocerla no termina en establecer su porqué y su cómo, ya que es menester también echar de ver su para qué, esto es su sentido. El advenimiento de la inquietud por lo psicológico, así como el ocaso del monismo materialista, desencadenó en la psiquiatría una crisis donde la sustitución del referente energético por el substancial, impulsó nuevos modos psicológicos, psicoanalíticos y sociales de concebir las dolencias mentales.

Palabras-clave: Locura, psiquiatría, persona, fundamento. 


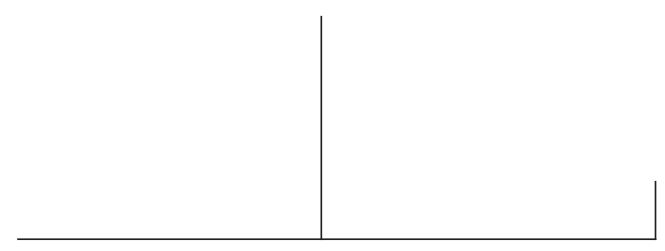

La "locura", cualquiera sea su versión modal, es una eventualidad de proceso de personalización, no un acaso gratuito o azaroso, ni el obligado efecto de una causa. Conocerla no termina en establecer su porqué y su cómo, ya que es menester también echar de ver su para qué, esto es su sentido. El advenimiento de la inquietud por lo psicológico, así como el ocaso del monismo materialista, desencadenó en la psiquiatría una crisis donde la sustitución del referente energético por el substancial, impulsó nuevos modos psicológicos, psicoanalíticos y sociales de concebir las dolencias mentales. La extensión de la duda metódica al Sujeto, la práctica de la sospecha para ir más allá de lo manifiesto, y la promoción de la Escucha a un papel instrumental, principales operadores en el ahondamiento de la textura de lo mórbido dieron pie a la aparición de estudios psicopatológicos que revelaron de la imposibilidad de separar la teoría de la práctica. Y esto profundizó los cuestionamientos evidenciando que las concepciones teórico-científicas no alcanzan para abarcar la "locura" porque su realidad concreta es diferente de las abstracciones con las cuales se intenta explicarla. Cada tematización que las sucesivas teorizaciones han hecho de ella - psicoanalítica, biológica, comunicacional etc. - tiene su propio estilo categorial. Usar la idea de catexia es válido para la conceptualización energética de las pulsiones, no para referirse al estrato biológico de las perturbaciones mentales donde, entre otras, rige la noción de retroalimentación y de campo neuronal. Sin embargo el recurso a una concepción antropológica respeta estas diferencias, ya que considera los problemas en un nivel diferente donde rigen ideas de carácter no lineal, dinámico y totalizador. Una de ellas, eje que orienta y condiciona la textura de la persona es aquélla de fundamento. ¿Cuáles son sus notas más destacadas? ${ }^{1}$

1. Un texto escrito difiere del hablado: permite aclarar ciertos puntos y afinar otros, pero básicamente debe respetar la médula de aquello que se dijo. Por este motivo el lector encontrará diferencias expositivas entre el texto que ahora publico y mi participación oral en el último Congreso de psicopatología fundamental. 


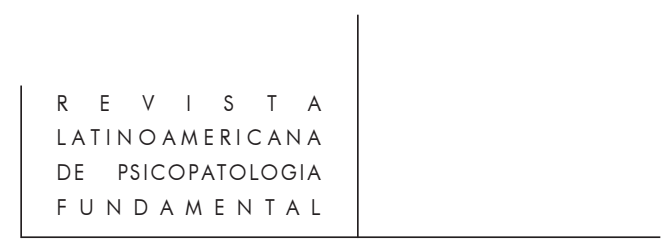

\title{
Fundamento
}

\author{
O eco, no caminho \\ entre a cidade e a fazenda, \\ é no fundo de mim que me responde.
}

Carlos Drummond de Andrade

La constelación semántica del vocablo fundamento está integrada por vocablos con oficio verbal - fundar y fundamentar -, sustantivo - fundamento, fundación y adjetivo, como lo tiene el término fundamental. ¿Qué expresan estas diversas flexiones cuya etimología común remite al latín fundus?

Una de sus significaciones que denomina el fondo de una cosa, su base y cimiento, menta la hondura de algo, el fondo de un pozo o del mar, remite a la idea del asiento sobre el cual se dispone, construye o edifica algo. En efecto, se "echan", los fundamentos de una institución, se funda un partido político estableciendo sus bases, o se genera un movimiento de opinión, realizando acciones que implican hacer algo nuevo desde lo hondo y primordial.Y desde lo bien fundado se erigen edificios, teorías, se establecen relaciones y vínculos que implican el desarrollo y la valoración del espacio imaginario vertical que, dando cabida, a las fantasías relativas a lo hondo y a la hondura, asociadas al cavar, remiten a la intimidad, a lo nutricio, a lo sustentante. Fundamento implica en esta acepción, aquello capaz de servir de sostén a una construcción física o ideal, alimentarla y anclarla sólidamente.

Una segunda significación, más próxima a lo racional e intelectual, está referida a un modo de argumentar cimentando el discurso en proposiciones firmes y coherentes. Fundamento se aproxima así, aunque sin confundirse con ella, a la noción de axioma, como lo mentamos al referimos a los fundamentos de la geometría euclidiana, del desarrollo teórico o el de un planteo práctico. Y si en su primera acepción, fundar evoca el área de la construcción, en la segunda lo hace a aquélla de verdad y de verosimilitud.

Una tercera acepción, derivada esta vez del sustantivo fundo, remite a la heredad, a la finca, al predio rústico y a la tierra solariega acordando predominancia a la referencia a la tierra, a su fuerza mítica, afincadora y primigenia. Mentando un amplio abanico semántico que va de lo existencial y argumentativo a lo agrario, esta constelación semántica designa lo básico, sustentador, consistente, firme, con peso y densidad. Fundar otorga sostén, da firmeza y enriquece, fundamento es el sostén, el arrimo, el soporte, el amparo, la ayuda, y fundamental lo que, al prestar estos servicios, arraiga.

Llegados a este punto conviene seguir la via apofántica, para realzar lo positivo por medio de lo negativo. ¿Qué no es fundar, fundamento, o fundamental?

Siguiendo el eje vertical en el cual se inscriben las significaciones de esta constelación semántica, un primer acercamiento descarta lo superficial, lo prescindible, 


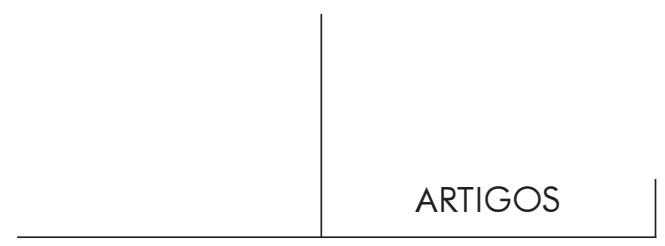

lo pasajero y lo liviano. Lo fundamental tiene peso, aquilata valores, está hundido en la existencia y es duradero. Mas si bien fondo y superficie son opuestos, no se excluyen, pues se complementan en tanto polos entre los cuales existe una relación de continuidad semejante a la de los modos del "fuera" y "dentro" de una cinta de Moebius. Por otra parte ni fundar, ni fundación, ni fundamental son oficios del hacer, no la esencia o lo previo de algo ni del ser. Tampoco implican detenimiento porque, aunque duradera, la fundación no es instalación, ni el fundar implica. No se funda de una vez para siempre, sino que su índole es ser eje de un tejido en expansión, es decir de una red de relaciones críticas y criticables en constante movimiento histórico.

Tampoco lo fundamental es meramente individual, aislado, retraído, clausurado o apartado. Un nonocido grabado, que representa la re-fundación de Buenos Aires, muestra, a un costado del palo de justicia, a Juan de Garay hincado en tierra, espada em mano, señalando el lugar donde funda y asienta. El gesto apunta hacia lo hondo y abierto de la materia donde erigirá y edificará la ciudad. El decir de la actividad fundante no se detiene en lo manifiesto, ni queda prendido en el "más-decir" del símbolo sino que introduce un silente "tras-decir". El palo de justicia, referente firme para erigir algo más allá de afincar en la materialidad - el Adelantado funda un pueblo - envía a leyes ordenadoras, prescripciones y prohibiciones, reguladoras de la convivencia. Allende el individuo, lo fundamental involucra al grupo humano, lo liga a la tierra, y permite, desde este acto, habitar de asiento. Y si bien en ninguno de sus oficios - verbo, sustantivo o adjetivo - esta constelación semántica remite a un elemento, tampoco es un acúmulo de significaciones, sino un sistema reticular de significancias históricas cuya función, fontanal y nutricia, más respalda que origina porque sostiene, no genera. Su campo no se centra pues ni en el porqué ni en el cómo - "la rosa es rosa porque es rosa" - y nombra algo más arcano, cuanto más se penetra en él.

¿De qué modo penetramos los humanos, nos arriesgamos, nos entregamos y hacemos pie en lo fundamental?

\section{Profundizar}

$$
\begin{array}{r}
\text { Mira amigo, cuando libres } \\
\text { tu pensamiento al mundo } \\
\text { cuida que sea, ante todo, } \\
\text { denso, denso. } \\
\text { Unamuno }
\end{array}
$$

Los humanos vamos haciendo camino en la espesura de la vida para calar en ella y como la sonda que arroja el marinero al agua para conocer su hondura, profundizamos en el estudio, profundizamos en el amor, y arriesgándonos inquirimos, preguntamos, buscamos, ahondamos más allá de lo manifiesto, de lo conocido y de 


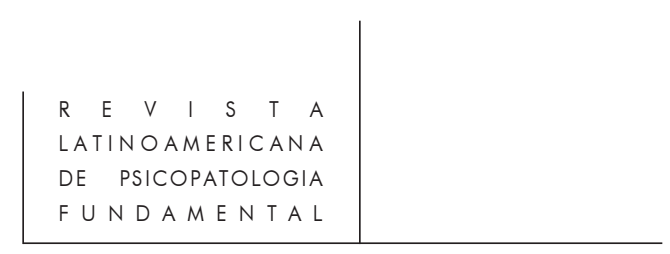

lo sabido. Esta actividad de internarse en lo inconmensurable, eterno e infinito, en un rumbo no cuantitativo, ni cronológicamente mensurable, es profundizar. El fundamento, la tierra, el asiento, el solar, el grund, señaló Heidegger, es Abgrund, esto es abismo, tajo constitutivo de la persona, y, al calar, ahondamos profundizando.

Por esta hendidura nos dejamos penetrar por los Otros quienes se introducen por los intersticios del espejo narcisista cuando, para profundizar en nosotros mismos, logramos hacernos trasparentes. Más que lograr desvelar notas de más en más hondas, profundizar busca trasparentar, y quien profundiza anda, caminante y peregrino, en el espesor y densidad del abismo de la existencia. Operación riesgosa, este trayecto trascurre en el corazón de la vida no caída, ahonda en la ancha consistencia de la vida, animada por la esperanza de interiorizar en las cosas.

A este proceso le interesa el sendero, la andadura, no la meta, para lo cual se desarrolla en un procedimiento, abismarse en un proceso sin fin que ahonda trasparentando la opacidad de la apariencia de la sustancia y el tras-decir del decir. Y al ir más allá de la condensación ocasional de la materia, de su crasitud y gordura, permite surgir lo situado más allá de su aparecer. Al profundizar, la Mirada capta lo nuevo para ella, embiste opacidades, y designa el lugar para la metáfora para decir lo indecible. Y cuando esto sucede lo trasparente surge en la "noche sosegada" del poetizar actividad que, por centrar lo convencionalmente aguardado, es fundamental para el desarrollo de la praxis psicopatológica. Paradojalmente, la trasparencia implica descender, abismarse en la intimidad de las cosas, mirarlas e ir a su encuentro, encuentro de profundización y descenso en el seno del abismo, que se realiza en la Noche, no en las tinieblas, del misterio del sufrimiento. Al internarse en el amor, profundizar hace des-aprender el miedo, pero trae consigo el riesgo de venirse abajo, en la caída vertiginosa del estado de enajenación, ya que profundizar es operación que des-instala, frágil, aunque no necesariamente débil.

Su tiempo lento, paciente, tardo, pausado como el del agua penetrando en la tierra, suscita un horadar deambulando, y recorre la calidez. Caminar es cálido y el calor es el signo de una profundidad. Y el habla se refiere a la "calidez" de un encuentro porque el abismo de lo fundamental es cálido, nunca quemante.

\section{"No saber"}

Entreme donde no supe y quedeme no sabiendo toda ciencia trascendiendo.

S. Juan de la Cruz Copla IV

Profundizar es caminar hacia un fondo que se ahonda a medida que penetramos en él y un fundo done, enraiza la vida asentándose en la fluencia del sentido, como 


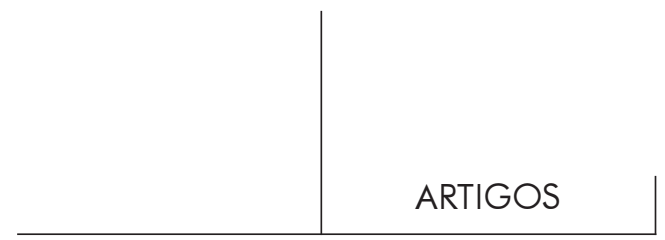

lo hace el argumento fundado cuyo desarrollo, denso y sesudo, inaugura un misterioso saber. No hay modo de existir sin fundación en apertura que permita re-fundar lo que, por múltiples motivos, necesita acrecentar o recuperar su solidez.

Lo fundamental, légamo de la existencia, barro que una vez moldelado, presta solidez a la edificación de la persona carece, sin embargo, de existencia propia. El fundamento no tiene carácter abstracto, discursivo o imaginario sino servicial. Podemos tratar de explicarlo, conocer su cómo, sus vicisitudes, sus desarrollos pero nunca terminamos de aprehenderlo porque se va haciendo en su mismo andar. Modalidad inmedible, está inmerso en la persona misma, en su para qué. El fundamento de lo fundamental es servir "para".

Afirmar que el sufrimiento mental, su tramado psicopatológico, ha de abordarse también desde el fundamento, es inasible para una disciplina científica concebida al modo positivista. Pero el choque con ella no es inútil, porque la chispa que produce evidencia un carácter de la existencia, remitente a su para qué, esto es, a su sentido. El fundamento, andar medular y meduloso configura en misterio, servicio y sentido, un modo de ser.

\section{Fundamentos de la persona}

La persona se va haciendo "en" y "con” la situación y lo diferente a ella, constituye un rico venero a estudiar. ¿Qué significa ésto?

En efecto, la partícula "en" envía a la ubicación temporal o espacial de algo. Decimos, por ejemplo, que Navidad se festeja "en” diciembre, subrayando los parámetros diacrónicos; París, aseguramos, está “en” Francia, indicando su ubicación espacial, y repetimos lo mismo todas las veces que usamos esta preposición. No se trata, sin embargo, de algo absoluto pues también decimos en-cargar, en-amorar etc. creando términos donde la partícula, usada ahora como pre-verbo, menta el "estar ubicado dentro" ya que quién en-carga, trasmite y comunica un cargo, un asunto, un negocio quien en-amora, busca ubicarse "dentro" del amado etc. "En" dice, pues, una peculiar relación de ubicación donde los protagonistas "en-cajan" uno dentro de otro en mayor o menor armonia, encaje que, de remitir a la situación vivida, alude al amplio y fundamental fenómeno antropológico de "estar habitando". Un ejemplo aclarará el punto.

Un hecho banal de la vida cotidiana es despertar por la mañana e ir tomando consciencia de estar entonado afectivamente en una situación. En este estado de ánimo, angustiado, alegre, preocupado etc. me hago presente en la realidad y voy morando en ella: me higienizo, desayuno, leo los periódicos y, por ejemplo, concurro a la consulta hospitalaria. Algunas de estas posibilidades me caen bien, y las llevo a 


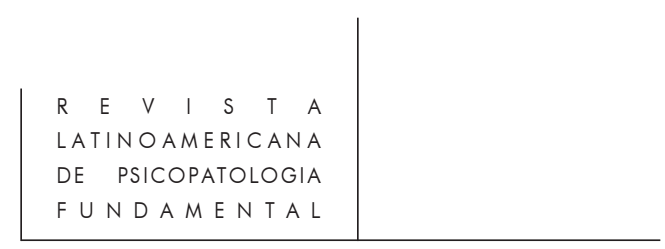

cabo sin mayores problemas, postergo otras para más adelante, y otras generan conflictos, las olvido, las paso por alto etc. En otras palabras, habito "en" estas diversas situaciones donde optando, entonando en un temple determinado entre las diversas posibilidades ofrecidas por cada una de ellas. Habitar es hacerse cargo de las diversas situaciones, y elegir, decir sí o nó a lo que me solicitan no sólo estar. Este modo de "hacerse-cargo" supone, además, relacionarse con objetos - manejo mi automóvil, tomo el ascensor etc. - y outras personas con las cuales anudo vínculos y me comunico. El encuentro, fenómeno referente a la constitución óntica de la persona, es otro fenómeno fundamental que se entrelaza con el estar habitando en un circuito procesal constituido "con" lo diferente a sí mismo, sean cosas, objetos, personas o circunstancias. Un estudio psicopatológico ha de atender a este sistema que se evidencia en los estados de ánimo, las elaboraciones, rechazos, opciones, vínculos y modos de comunicarse. Hacerse cargo, víncularse y comunicarse configuran las operaciones propias de este circuito antropológico fundamental. ${ }^{2}$

Ma si bien "estar habitando" y "encuentro" son concreciones del "en" y del "con" fundamental de la personalización no son las únicas pues, la persona se hace en unidad sistémica con diversas situaciones que son cristalizaciones parciales de la realidad. Conocerla y conocerse a sí misma, versiones polares del fenómeno de cognición, se diversifican en operaciones de inteligir y aprender que al intercambiarse y entretejerse con la mismidad - me reconozco el mismo a pesar de tener diversas identidades según sean las circunstancias - permite presentificarse de modo adecuado. A su vez "conocer-la-realidad" y "reconocerse-en-mismidad" individual, colectiva e histórica remiten a la presentificación cuyo modo concreto es "encarnarse" fenómeno que implica necesariamente el concurso de lo diferente, esto es en los Otros y a los otros.

Conocer, re-conocerse y en-carnarse son operaciones de otro circuito constitutivo fundamental de la persona que se articula con el primero en una red ecosistémica donde cada uno de ellos es "dato de" una totalidad constructa. Y, cuando se modifica uno también lo hacen los otros dentro de cierto rango de tolerancia. Conocer y saber acerca de los desbordes y alteraciones de su calidad es tema propio a la psicopatología.

Tampoco agota el tema de los fundamentos de la personalización, detectar y develar la interacción entre estos circuitos, y otra puesta entre paréntesis, esta vez de las manifestaciones de cada uno de ellos de sus modos constitutivos y operativos muestra que ir haciéndose "en" y "con" la situación, supone una existencia de la

2. Para más detalles acerca del tema remito a mi libro Persona y personalización. Buenos Aires, Carlos Lohlé, 1989. 


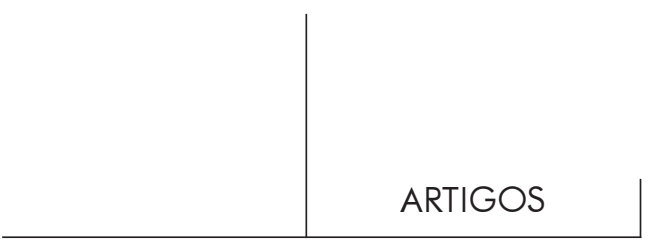

urdimbre fundamental y primigenia en la cual se entretejen los diversos circuitos. En efecto, la personalización se constitute con una actividad, un ímpetu - el thumos de los griegos - a la cual concurren solidariamente diversas pulsiones. Se trata de fuerzas con carácter sustantivo, energético e informacional orientadas hacia la obtención de algo, con dos versiones, Querer y Poder, íntimamente entrelazados cuyo campo es la actualidad. A la primera remite la psicopatología al estudiar la necesidad, el deseo, la petición - o demanda como suele traducirse el vocablo usando de un galicismo que atenúa su intensidad - y la gana. En términos generales, estas actividades están dirigidas a plantear y satisfacer apetitos dirigidos a obtener lo ausente que se patentiza, de modo predominante, en producciones imaginarias. Por su parte el Poder, fenómeno relacionado con ejercicio de la fuerza pulsional, conectado a la agresión con sentido creativo o destructivo, se diferencia del Querer en que su presentificación, genera relaciones de subordinación, muchas veces, vehiculizadas con intenciones de sometimiento. Su destino es, por lo tanto, fundar el dominio, o integrarse al servicio, según esté a disposición de sí mismo o del Otro. Mas si por determinados motivos, el funcionamiento armónico de ambos conjuntos se quiebra o rompe pueden engendrarse trastornos psicológicos. Las perversiones son algunos de ellos. ${ }^{3}$

Un segundo hilo, aquél de la confianza antropológica sostiene el hecho de erigirse en la realidad haciendo pie en ella. Para poder confiar he de descontar con la consistencia, asistencia y resistencia de lo otro y los Otros, esto es de tener un suelo donde afirmarme, y una tierra donde ir labrando mi morada. Y si los trastornos de las pulsiones remiten a la ausencia, aquellos de la confianza básica lo hacen al vacío creado por la traición a una promesa, con cuya existencia cuenta. El drama de la drogadependencia lo muestra en su más descarnada faceta. Y por último un tercer hilo de la urdimbre, nota propia y apodíctica de la condición humana, es su limitación concretada en esa carencia fundamental que alimenta la menesterosidad no podemos existir sino con el Otro y lo otro - y la mortalidad que nos dice nuestra transitoriedad, inquietante pregunta que nos insita a la búsqueda del sentido de nuestra vida.

\section{Resumos}

A loucura, qualquer que seja sua versão modal, é uma eventualidade do processo de personalização, não um acaso gratuito ou de azar, nem o efeito obrigatório de uma causa. Conhecê-la não é estabelecer seu porquê e seu como, uma vez que também é 


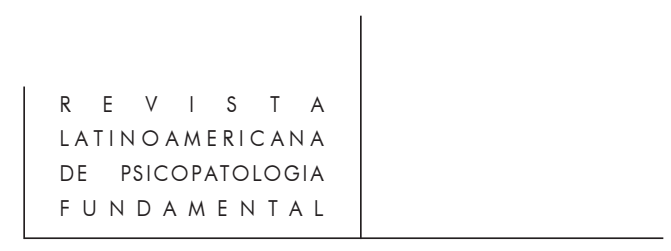

fundamental encontrar seu para que, isto é, seu sentido. O advento da inquietude pelo psicológico, bem como o ocaso do monismo materialista, desencadeou na psiquiatria uma crise onde a substituição do referente energético pelo substancial deu impulso a novos modos psicológicos, psicanalíticos e sociais de conceber as doenças mentais.

Palavras-chave: Loucura, psiquiatria, pessoa, fundamento.

La démence, quelque soit ça version c'est une éventualité de processus de personalization, pas un hasard gratuit ou malchanceux, ni l'effet obligatoire d'une cause. Son connaissance ne finit pas en établir son parce que et son comme, puisque c'est mister aussi voir son pour que, celui-ci c'est son sens. L'avènement de l'inquiétude pour le psychologique, ainsi que le couchant du monisme matérialiste, a declenché dans la psychiatrie une crise où le remplacement de la référence énergétique pour la substantiel, a stimulé nouvelles façons psychologiques, psychanalytiques et sociaux de concevoir les malades mentaux.

Mots-clés: Démence, psychiatrie, personne, fondement.

Madness, whatever its modal version, is much more an eventuality in the personalization process, than an accident that happens by chance, or the obligatory effect of a cause. Knowing it, is not asking "why?" of "how?", since the fundamental question seems to be "what for?", in order to find out its meaning. The advent of disquiet by the psychological, as well as the fall of the materialistic monism, started a crisis in psychiaty. The substitution of the energetic by the substancial reference has driven to new psychological, psychoanalytical and social modes of conceiving the mental diseases.

Key words: Madness, psychiatry, person, basis. 